\title{
Paris-type morphology a common feature on Lunularia cruciata colonised by Glomus and Gigaspora fungi
}

\author{
H.M.A.C. Fonseca*, A. Azevedo* and M.L. Pereira*,** \\ * Department of Biology, University of Aveiro, 3810-193, Aveiro, Portugal \\ ** CICECO, University of Aveiro, 3810-193, Aveiro, Portugal
}

Arbuscular mycorrhizal fungi (AMF) are ubiquitous underground symbiotic associations between most plants and fungi from the phylum Glomeromycota. From this symbiosis plants generally improve their capacity to obtain less mobile soil nutrients (like phosphorus) and increase resistance against biotic and abiotic stresses. Concomitantly the fungus has access to host carbon photosynthates. As obligate symbionts these fungi require always a host to survive, hence dual cultures is an obligatory laboratory requisite to maintain and multiply live Glomeromycota fungi. These cultures are mainly of three sorts: 1) Open pot cultures, 2) in vitro cultures with Ti DNA transformed root systems, 3) and in vitro cultures with L. cruciata [1], presented here. The internal mycelium of AMF usually assumes one or both of the morph-types named Arum (first described on Arum maculatum) and Paris (observed in Paris quadrifolia) [2]. The Paris-type morphology is characterized by hyphae with an intra-cellular growth, from cell-to-cell, forming coils and arbusculate coils. The Arum-type shows mainly intercellular hyphae growth, longitudinally between cells, with the arbuscules mounting upright on short intra-cellular branches.

This study presents the first comparative morphologic characterization of 4 species of AMF grown in vitro with Lunularia cruciata (L.) Dumortier ex. Lindberg. Glomus clarum Nicol. \& Schenck (CNPAB 005), G. intraradices Schenck \& Smith (MUCL 43204), G. proliferum Dalpé \& Declerck (MUCL 41827); and Gigaspora margarita Becker \& Hall (CNPAB 001) internal hyphae share the same morph-type of L. cruciata colonization: the Paris-type. Stable and viable monoxenic cultures of AMF with L. cruciata were first presented by Fonseca and co-workers in 2006 [1] for G. intraradices and G. proliferum on Petri dish (Fig. 1.1). In this work we bring two more species (G. clarum and Gi. margarita) cultured in vitro with L. cruciata, on bi-layer medium in flask containers (Fig. 1.2). The production of spores occurred mainly, among the rhizoids, between overlapping thallus and over the thallus (Fig. 1.3). Only the Glomus species produced spores within the medium.

L. cruciata belongs to a group of complex thalloid liverworts with an internally differentiated anatomy: an upper epidermis forming air chambers where the chlorophyllous cells are located, a conspicuous vacuolated parenchyma, and the lower epidermis with its scales and rhizoids (Fig. 1.4). All four species show highly similar architecture of colonization with most fungi distributed in the thallus' midrib parenchyma, and with internal mycelium architecture compatible with the Paris-type colonization (Figures 1.5 to 1.8). Although consistent the occurrence of Paris-type colonization among these four species, more species needed to be examined before a generalization can be given. The availability of AMF isolates for research at international fungi collections and laboratories is limited, and from these axenic isolates for in vitro culture are very few, which hinders the prove of the hypotheses that Paris-type colonization is the main pattern of hyphae colonization in L. cruciata mycothallus.

\section{References}

1. Fonseca H.M.A.C. et al., Mycorrhiza, 16:503-8, 2006.

2. Read D.J. et al., Phil. Trans. R. Soc. London B, 355:815-831, 2000.

Grants from Research Centre on Ceramic and Composite Materials (CICECO) from Aveiro University (Portugal) and Pest-C/CTM/LA0011/2011-FCT are acknowledged. 


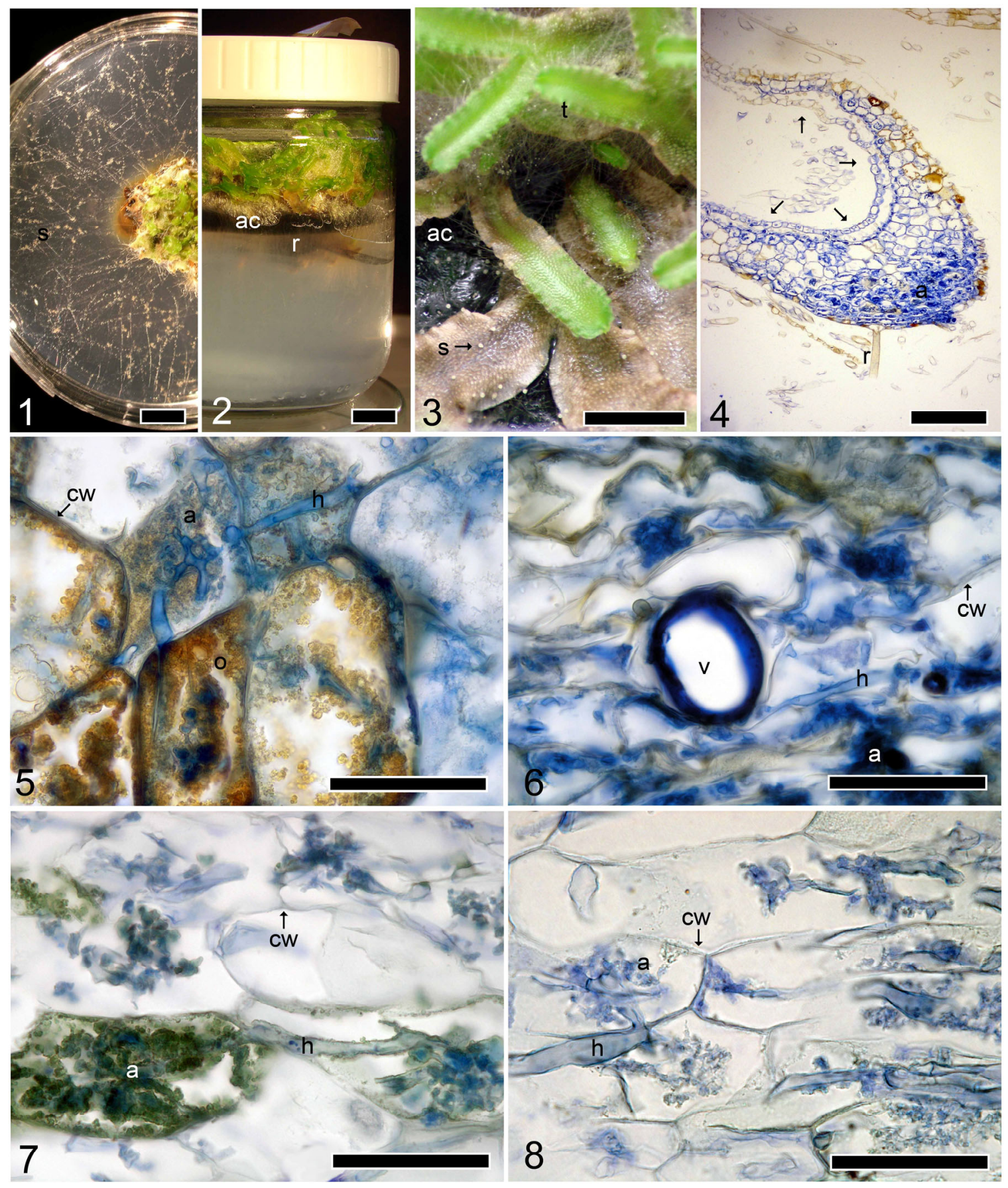

Fig.1 - Lunularia cruciata (Lc) colonized by 2 genera of arbuscular mycorrhiza fungi. 1) Example of culture using Petri dish. (s) Cluster of Glomus proliferum spores along external hyphae. 2) Culture in a flask container. (ac) Activated-Charcoal layer; (r) rhizoid zone. 3) Upper view of a culture of Gigaspora margarita showing Lc thallus ( $\mathrm{t}$ ) with rhizoids. (s) One of many spores over older brownish thallus. 4) General view of the anatomy of Lc thallus showing an upper epidermis (arrows), followed by the photosynthetic zone, then the storage layer of parenchymatous cells and finally the under-epidermis with scales and rhizoids (r). (a) Arbuscular zone where fungus is more conspicuous. 5) Detail of Lc thallus colonized by G. intraradices showing hypha crossing different plant cells forming arbuscules. (cw) Plant cell wall; (h) Intracellular hyphae; (o) Oil cell showing the remaining lipids after the $\mathrm{KOH}$ cleaning process. 6) Colonization by $G$. proliferum showing among other details a fungus vesicle (v). (a) Collapsed arbuscule. 7) G. clarum internal mycelium traverses plant cells and forming arbuscules (a). 8) Finally, a detail of the anatomy of Lc with by Gi. margarita showing the same pattern of colonization generally referred as Paris-type. Bars: 1-2, $10 \mathrm{~mm} ; 3-5 \mathrm{~mm} ; 4,500 \mu \mathrm{m} ; 6-8,40 \mu \mathrm{m}$. 